\section{Living ancient history}

Introducing Geology: The Earth's Crust Considered as History. By D. V. Ager. Pp. $256+21$ plates. Second Edition. (Faber and Faber: London, February 1975.) £3.95, hard bound; $£ 1.75$, paperback.

THis is a book about very ancient history. It reviews, in readable language, the geological evolution of the British Isles, with some references to other parts of the world. Since the first edition appeared in 1958, there has, as everyone knows, been a revolution in the earth sciences: continental drift has now been proved, and seaffoor spreading, subduction and plate tectonics have all become recognised as aspects of the surface layers of a planet that is probably expanding. This new edition adds a bold but sufficient outline of these exciting developments to the first chapter and applies them at later stages; for example, the mid Palaeozoic troughs are seen as resulting from the opening of a proto-Atlantic between plates bearing America and Europe on their backs; plates which later closed to produce the Caledonian Mountains. Similarly, the break-up of the former southern continent of Gondwana under the influence of convection currents in the upper mantle is used to illustrate an important stage in geological history. In that and other ways, the reader is introduced to modern ideas of global tectonics.

The general treatment remains the same: the consideration of groups of geological epochs and systems. Thus, the chapters entitled "Oldest Rocks of All" covers the $4 \times 10^{9}$ years of Precambrian time; the "Oldest Rocks with Fossils", the Cambrian, Ordovician and Silurian systems; "Dry Land and Shallow Seas", the Devonian and Carboniferous. Each chapter is illustrated with maps showing the general outcrops of the relevant strata in Britain; and palaeogeographical diagrams, some original, some based on the works of L. J. Wills and F. W. Shotton, are included. There are illustrations of typical fossils but there is a minimum of fossil names and almost no mineral names. The chief rockmaking and physiographical processes are described as they become relevant and they are illustrated with well produced plates, prepared mainly from Geological Survey photographs.

In one respect, Professor Ager has again been overtaken by events. His chapter entitled "The Long Quiet Episode", devoted to the Rhaetic, Jurassic and Cretaceous, was very suitably named when he prepared this second edition; as he says, it was reason- able to think of the European plate sailing peacefully at this time. But last November, the North Sea petroleum operators released their geological results, showing that the later stages of Jurassic time were not all quiet in the British area. There were in fact major rift-forming movements in the centre of what is now the North Sea, accompanied by modest volcanic activity and followed by extensive erosion. The rift profoundly affected Cretaceous sedimentation, which had filled up the trough by the time that the Tertiary basin covered it. The effects of these 'Kimmerian' movements explain the absence and reappearance of Jurassic strata in various parts of the North Sea Basin, and make us realise that the apparent continuity of the Jurassic outcrop across England is no indication of what happens in the third dimension. There will be material for a third edition of this book, but in the meantime it is none the worse for having missed the Kimmerian. Geology is, after all, a living and developing subject, and this historical approach to the country which so much influenced its progress is a good introduction to it.

Kingsley Dunham

\section{By jove}

The Jupiter Effect. By John Gribbin and Stephen Plagemann. Pp. 136. (Macmillan: London and Basingstoke, 1974.) £3.95.

". . . all we have done is to gather in one volume data from scattered sources and look at them anew..."

And a splendid job the authors have made of weaving a complex, yet neat, design from the geophysical observations they have used. There may be a piece or two still missing, and the picture might well fall apart when lifted by the corner, but nonetheless it is a readable yarn which inquisitive citizens will enjoy; and seismologists may envy the authors' courage in undertaking to predict that the next great earthquake on the San Andreas Fault will occur in 1982, give or take a couple of years.

In that year the planets of the Solar System will be in conjunction with every other planet for the first time in 179 years. On the evidence of correlations-observed since the 17th Century - between peak sunspot activity and peak tides raised on the Sun, the authors predict a dramatic increase in activity for 1982 . This, they argue might initiate a chain reaction through the interaction of solar wind and cosmic rays with the upper atmosphere, thereby affecting world wide atmospheric circulation patterns which in turn would change the Earth's rate of spin to provide the relatively small triggering force required to raise the 'normal' level of seismicity in highly strained belts. Observational evidence is well documented, and the circumstantial links in the chain plausibly argued. In the process the authors have provided lay readers with an educational glimpse of several geophysical processes and the geophysicist with sufficient stimuli to follow their suggestion to "wonder how such an interaction could work".

Why pick especially on the San Andreas Fault? Well for one thing it must attract wider interest (and a larger market) than, say, the Highland Boundary Fault and for another it is so well studied, so closely knitted instrumentally, that even the seismologists concerned are confident enough to venture predictions (though none so closely as $1982 \pm 2$ years). The latest of these professional forays into the fashionable field of earthquake prediction was published in Nature a few months ago and rules out the area between San Francisco and Parkfield for a really large earthquake before 1999 , but accepts the possibility of a moderately large disturbance from 1981 onwards. Those predictions were based on recent observations of the rate of change of P-wave velocities, on which readers are brought up to date in an appendix to The Jupiter Effect (a title which neatly fits a book that unashamedly and provocatively attempts a geophysical explanation for the predictions of astrologers). Gribbin and Plagemann did not have time to fit this more recent work into their jigsaw and, in any case, they persuade us by other published evidence that the area on the San Andreas which is primed for triggering lies nearer to Los Angeles, south-east of Parkfield.

Even if such forecasts turn out to be less precise than hoped for, there is little doubt that California, as well as other thickly populated seismic areas, will suffer from great earthquakes which cannot be avoided unless lubrication can be applied to smooth the rate of release of stored energy. And as it would be a very brave (or ill judged) decision to pump water along the San Andreas Fault, the authors return to the unglamorous duty of spelling out the precautions which town planners and individuals can take to mitigate the inevitable effects. That their common sense statements of the obvious are considered worth printing demonstrates the social nature of the problem. The most sophisticated of observational and analytical efforts will contribute nothing to ease the disaster confronting a dam which, on the face of it, is intended to staple the edges of the Pacific and North American plates.

H. I. S. Thirlaway 